\title{
Composition and spectra of copper-carotenoid sediments from a pyrite mine stream in Spain
}

Javier Garcia-Guinea $^{1 *}$, Marta Furio ${ }^{1}$, Sergio Sanchez-Moral ${ }^{1}$, Valme Jurado ${ }^{2}$, Virgilio Correcher $^{3}$, Cesareo Saiz-Jimenez ${ }^{2}$

${ }^{\mathbf{1}}$ Museo Nacional de Ciencias Naturales (MNCN-CSIC). Calle José Gutiérrez Abascal 2, 28006 Madrid, Spain, ${ }^{2}$ Instituto de Recursos Naturales y Agrobiología (IRNASCSIC). Avenida Reina Mercedes 10, 41012 Sevilla, Spain, ${ }^{3}$ Dpto. Dosimetría de Radiaciones, CIEMAT, Avenida Complutense 22, 28040 Madrid, Spain.

*E-mail: guinea@mncn.csic.es; mfurio@mncn.csic.es; ssmilk@mncn.csic.es; vjurado@,irnase.csic.es; saiz@,irnase.csic.es; v.correcher@,ciemat.es;

\section{ABSTRACT}

Mine drainages of La Poderosa (El Campillo, Huelva, Spain), located in the Rio Tinto Basin (Iberian Pyrite Belt) generate Carotenoid Complexes mixed with Copper Sulphates (acronym CCCuS) presenting good natural models for the production of carotenoids from microorganisms. The environmental conditions of Rio Tinto Basin include important environmental stresses to force the microorganisms to accumulate carotenoids. Here we show as carotenoid compounds in sediments can be analyzed directly in the solid state by Raman and Luminescence spectroscopy techniques to identify solid carotenoid, avoiding dissolution and pre-concentration treatments, since the hydrous copper-salted paragenesis do not mask the Raman emission of carotenoids. Raman spectra recorded from CCCuS sample exhibit major features at approximately 1006,1154 , and $1520 \mathrm{~cm}^{-1}$. The bands at $1520 \mathrm{~cm}^{-1}$ and $1154 \mathrm{~cm}^{-1}$ can be assigned to in-phase $\mathrm{C}=\mathrm{C}\left(y^{-1}\right)$ and $\mathrm{C}-\mathrm{C}$ stretching $\left(y^{-2}\right)$ vibrations of the polyene chain in carotenoids. The in-plane rocking deformations of $\mathrm{CH}_{3}$ groups linked to this chain coupled with $\mathrm{C}-\mathrm{C}$ bonds are observed in the $1006 \mathrm{~cm}^{-1}$ region. X-irradiation pretreatments enhance the cathodoluminescence spectra emission of carotenoids enough to distinguish organic compounds including hydroxyl and carboxyl groups. CCCuS could be a biomarker and useful proxy for understanding remote mineral formations as well as for terrestrial environmental investigations related to mine drainage contamination including biological activity and photo-oxidation processes. 
KEYWORDS: Carotenoids, Biomarker, Riotinto, Raman, Cathodoluminescence, Remote-Sensing, Copper-sulphates.

\section{INTRODUCTION}

Carotenoids and copper sulfate mixtures are scarcely studied by spectroscopic methods because of its poorly crystalline structure, unstable hydration states, carotenoids variety, unpredictable impurities and low intensity of the Raman emission from the copper sulfate masses. One of the world's richest regions of poly-metallic sulfide deposits is the Iberian Pyrite Belt located in the southwest of the Iberian Peninsula. This area includes the Rio Tinto Basin, a natural highly acid rock drainage system due to the creation of highly acidic conditions via the weathering of rocks containing base metal sulfide minerals with abundance of pyrite and chalcopyrite. This basin contains an interesting extremophile biological activity [1-3]. Studies on these acid drainage materials of Rio Tinto Basin were performed to test analytical devices also operating onto Mars surface, such as robotic drills [4] or chromatography-mass spectrometers [5]. Miniaturized versions of Raman-Photoluminescence and X-ray diffraction spectrometers are operating in the Opportunity and Curiosity rovers with new analytical facilities for determining minerals phases on basis to their molecular and structural configurations in the short and long atomic orders. Carotenoids are particularly interesting in plants and algae absorbing light energy for use in photosynthesis and protecting chlorophyll from photo-damage [6-9]. Rhodotorula mucilaginosa is an interesting example of a pigmented yeast, found in a copper mine in the province of Tucuman, Argentina, supporting high concentrations of $\mathrm{Cu}(\mathrm{II})$ and providing relationships among carotenoid production, copper bioremediation and oxidative stress associated to this yeast [10]. The separation of carotenoids by high performance liquid chromatography (HPLC) could provide: (i) carotenoids containing different end-groups; (ii) stereoisomers of carotenoids; (iii) geometrical isomers of carotenoids; (iv) configurational (optical) isomers of carotenoids. The choice of the specific HPLC column for separating stereo-isomers of carotenoids is critical, whereas the geometrical isomers of beta-carotene are best separated on an HPLC lime column; geometrical isomers of several other carotenoids abundant in fruits and vegetables can be better separated on a $\mathrm{C}_{18}$ reversed phase column [11]. Later, the separately purified carotenoids can be identified from their UV/visible and mass spectra and by comparison 
of their HPLC retention times and UV/visible absorption spectra with synthetic carotenoid patterns. Carotenoid synthesis is also induced by copper in the bacterium Myхососcus xanthus, the blue light was the only environmental agent known to induce carotenogenesis in this bacterium, since under blue light copper activates the transcription of the structural genes for carotenoid synthesis through the transcriptional activation of the carQRS operon [12]. Recent studies pointed to $\beta$-carotene detection by Raman spectroscopy as a possible biomarker in the Martian evaporite environment. [1315]. Carotenoids can be identified using Raman micro-spectroscopy by the characteristic Raman spectral bands centered at $1518 \mathrm{~cm}^{-1}$ and $1156 \mathrm{~cm}^{-1}$ [16]. Raman spectroscopy is a very sensitive technique detecting carotenoids into ionic salts since they not exhibit Raman emission. Laboratory driven Raman measurements performed on different proportions of mixtures obtained $\beta$-carotene Raman signals at the $10 \mathrm{mg}$. $\mathrm{kg}^{-1}$ concentration level in sulphates and halide matrices, interesting results that will aid in situ analyses on Mars. [17-19]. Unfortunately, common simple natural features such as hydration, small grain size of crystals, bacterial or fungi bioturbation, iron presence, photo-oxidation and chemical disorder generate near amorphous compounds with difficult determination by both Raman and X-ray diffraction techniques. The diodepumped solid state laser light of our Raman microscope $(532 \mathrm{~nm})$ produces detectable photoluminescence emission (PL) in many hydrous basic copper compounds, such as carbonates, sulfates, phosphates, silicates and chlorides. Frequent publications focus on $\beta$-carotene Raman-PL spectroscopy in solution [20] but rarely on natural sediments with solid carotenoid. Solid carotenoids in copper ores collected in nature seem scarcely studied directly by luminescence techniques. Here we analyze $\mathrm{CCCuS}$ complexes naturally formed into an open mining environment of copper brines exposed to the environmental weathering of the Rio Tinto Basin including biological activity and sequential humidity-desiccation cycles.

\section{SITE, SAMPLES AND METHODS}

In a field trip around the Iberian Pyrite Belt, on April 25, 2013, we observed on the surroundings of the abandoned La Poderosa mine, north of El Campillo (Huelva, Spain) a small, natural drainage stream with a light blue color and pH 6.4 (Fig. 1a). The stream which extended for only few tens of meters was not recent, as deducted from the mineral precipitation on the shores and in the end of the stream (Fig. 1a). Near the 
upwelling point formed blooms of a living alga tentatively identified as Dictyosphaerium sp. At some places, a tiny light blue mineral crust was observed on the water surface and, a dense green algal biofilm that enclosed numerous bubbles was evident upon removal of the crust. These bubbles were also previously described for cyanobacterial mats [21]. One month later, the stream was almost dry, but still retained its blue color, with very restricted green biofilm patches and extensive mixing of sediments and lysed algae (Fig. 1b). At this time the $\mathrm{pH}$ of the water/sediments was 7.5 and we collect dry samples of blue color to be analyzed. The taxonomical identification of the alga was supported by laboratory cultures and microscopic studies. The alga was characterized by oval cells surrounded by a mucilaginous envelope [22-23] (Fig. 1c,d). Species of the genus Dictyosphaerium grow in freshwaters where they commonly participate in the formation of green algal blooms. It has been reported that species of this genus are resistant to acidic waters and metal-rich waters [23]. In addition, the biofilm was formed by other microorganisms, which were also isolated and identified as Hyaloraphidium curvatum and Stilbella fimetaria. Hyaloraphidium curvatum is a rare representative of freshwater nanoplankton, which was traditionally classified as a colorless green alga but now recognized as a lower fungus [24]. Stilbella fimetaria has been recorded in saline and acidic soils from a Czechian natural reserve [25] and as endophytic fungus from marine algae [26]. Fungal DNA extraction, PCR amplification of DNA, clone libraries, sequencing and phylogenetic analysis have been extensively described by Jurado et al. [27]. The alga was identified using traditional morphological ebservations [22].

Natural and X-irradiatated CCCuS aliquots (Fig. 1b) were collected to be analyzed by Environmental Scanning Electron Microscopy with energy dispersive spectrometry probe (ESEM-EDS), X-ray diffraction (XRD), X-ray fluorescence spectrometry (XRF), Raman-Photoluminescence spectrometry (RPL), Differential Thermal and Thermogravimetric Analyses (DTA-TG), Thermoluminescence (TL) and Cathodoluminescence (CL) to record structural, molecular, chemical, thermo-gravimetric and photo-oxidation features of this CCCuS samples mainly composed by hydrous euchlorine-chalcantite carotenoid botryoidal complexes. The characterization has been rendered difficult by its poorly crystalline structure, variable impurities, hydration state and organic-inorganic mixture. For the scanning electron microscopy, a low-vacuum ESEM XL30 
microscope (FEI Co., USA) that enables high-resolution inspection and chemical analysis of nonconductive specimens was used. The ESEM microscope operating in low vacuum mode admits hydrated samples to be studied in their original state with the large field detector (LFD), since it is close to the sample to avoid electron losses. This ESEM can also work at high vacuum conditions with samples covered with sputtered gold, providing a better resolution in electronic images up to 1 micron diameter and more accurate elemental-chemical spot-analyses by Energy Dispersive Spectrometry (EDS). The ESEM resolution at high vacuum was $3.0 \mathrm{~nm}$ at $30 \mathrm{kV}$ (SE), $10 \mathrm{~nm}$ at $3 \mathrm{kV}$ (SE), and $4.0 \mathrm{~nm}$ at $30 \mathrm{kV}$ (BSE). While operating at low vacuum, it was $3.0 \mathrm{~nm}$ at 30 $\mathrm{kV}$ (SE), $4.0 \mathrm{~nm}$ at $30 \mathrm{kV}(\mathrm{BSE})$, and $<12 \mathrm{~nm}$ at $3 \mathrm{kV}(\mathrm{SE})$. The accelerating voltage was $200 \mathrm{~V}$ to $30 \mathrm{kV}$ and the probe current up to $2 \mu \mathrm{A}$ was continuously adjustable. The ESEM detectors are as follows: the LFD, Everhardt-Thornley or high-vacuum secondary electrons detector (SED), the IR-CCD camera, a solid-state BSE detector, and a new gaseous analytical electron detector (GAD). The X-ray diffraction study of a powdered sample of La Poderosa CCCuS complexes was performed using Xpowder software, which allows a full duplex control of the Phillips PW 1730/00 diffractometer

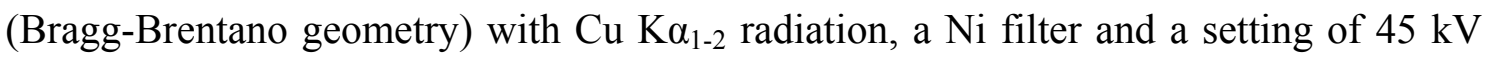
and $40 \mathrm{~mA}$. The XRD patterns were obtained by continuous scanning from 3 to $60^{\circ} 2 \theta$, with a receiving slit of $0.1 \mathrm{~mm}, 0.010^{\circ}(2 \theta)$ step size and a recording time per step of 2 s. Powdered CCCuS was pressed onto a silicon oriented sample holder. The X-ray diffraction experimental patterns of the powdered specimen were interpreted as those of low-crystallinity material together with accessory peaks spiking above the amorphous XRD band in which we cannot be able to index XRD spectra of crystalline phases. We explored on possible accessory minerals using XPOWDER software (www.xpowder.com) performing background subtraction, $\mathrm{K} \alpha_{2}$ stripping and chemical elements restrained to $\mathrm{C}, \mathrm{O}, \mathrm{Al}, \mathrm{Si}, \mathrm{S}, \mathrm{Ca}, \mathrm{Na}, \mathrm{K}, \mathrm{Cu}, \mathrm{Zn}, \mathrm{Mg}, \mathrm{Mn}, \mathrm{Fe}, \mathrm{Ti}, \mathrm{P}, \mathrm{Pb}$ and $\mathrm{Cl}$ previously detected by experimental XRF and ESEM-EDS analyses. These initial features improve the Boolean search-matching on the ICDD-PDF2 and RRUFF databases suggesting some PDF2 card files. Chemical XRF analyses of $\mathrm{CCCuS}$ samples were performed in a Magic Philips X-ray fluorescence spectrometer operating an ultrathin window and rhodium anode X-ray tube at $2.4 \mathrm{~kW}$. The equipment has two coupled flux and sparkling detectors in the spectrometric chamber. In addition, there are three collimators of 150, 300 and $700 \mathrm{~mm}$ for high resolution, quantitative analysis, and light 
elements analysis. Five analyzer crystals, LiF 220, LiF 200, Ge, PE and Px1, allow the detection of all the usual chemical elements from oxygen to uranium. The quantitative determinations were performed by IQ+ software of Panalytical-Philips. The powdered pellets (trace elements) were mounted using $8.0 \mathrm{~g}$ of sample and $3.5 \mathrm{ml}$ of elvacite with $20 \%$ acetone altogether pressed at $200 \mathrm{~kg} \mathrm{~cm}^{-2}$. The glass discs (major elements) were melted with $0.30 \mathrm{~g}$ of sample and $5.5 \mathrm{~g}$ of $\mathrm{Li}_{2} \mathrm{~B}_{4} \mathrm{O}_{7}$. The micro-Raman and photoluminescence spectra of samples were measured in a Thermo-Fischer DXR Raman-PL Microscope which has a point-and-shoot Raman capability of $1 \mu \mathrm{m}$ spatial resolution. We used the $100 \mathrm{X}$ objective of the confocal microscope together with a 532 $\mathrm{nm}$ laser source delivering $10 \mathrm{~mW}$ at $100 \%$ laser power mode. The average spectral resolution in the Raman shift ranging from 100 to $5000 \mathrm{~cm}^{-1}$ was $4 \mathrm{~cm}^{-1}$, with 900 lines/mm grating and $2 \mu \mathrm{m}$ spot size. The system was operated under OMNIC 1.0 software fitting working conditions such as pinhole aperture of $25 \mu \mathrm{m}$, bleaching time $30 \mathrm{~s}$; average of four exposures timed $10 \mathrm{~s}$ each. The simultaneous Differential and Thermo-gravimetric (TG) analyses of $5 \mathrm{mg}$ of powdered copper-sulfate aliquot was recorded simultaneously with a STA 6000 Simultaneous Thermal Analyzer Perking Elmer in N2 atmosphere with thermocouples PT-PT/Rh (Type R) operated under Pyris software. The thermal treatments were performed at heating rates of $10^{\circ} \mathrm{C} . \mathrm{min}-1$ from room temperature up to $900^{\circ} \mathrm{C}$. The sample was held in an alumina crucible and the reference material was also alumina. Thermoluminescence measurements were carried out using an automated Risø TL system model TL DA-12 provided with an EMI 9635 QA photomultiplier and the emission was observed through a filter (Melles Griot FIB006) with a centre wavelength of $513 \mathrm{~nm}$ and FWHM of $87 \mathrm{~nm}$. It is also equipped with a ${ }^{90} \mathrm{Sr} /{ }^{90} \mathrm{Y}$ source with a dose rate of $0.013 \mathrm{~Gy}-1$ calibrated against a $137 \mathrm{Cs}$ photon source in a secondary standards laboratory. All the TL measurements were performed using a linear heating rate of $5^{\circ} \mathrm{C} \mathrm{s}^{-1}$ from room temperature up to $500^{\circ} \mathrm{C}$ in a $\mathrm{N}_{2}$ atmosphere. Several aliquots of $5.0 \pm 0.1 \mathrm{mg}$ each were used for each measurement. The samples were carefully powdered with an agate pestle and mortar to avoid triboluminescence and sieved to obtain a grain size fraction under $50 \mu \mathrm{m}$. The incandescent background was subtracted from the TL data. The spatially and spectrally resolved cathodoluminescence emission of La Poderosa CCCuS samples were performed with MONOCL3 Gatan probe coupled to the ESEM system to record CL spectra and panchromatic and monochromatic plots with a PA-3 photomultiplier. The 
photomultiplier tube covers a spectral range of $185-850 \mathrm{~nm}$ and it is more sensitive in the blue parts of the spectrum. A retractable parabolic diamond mirror and a photomultiplier tube were used to collect and amplify the luminescence emission. The sample was positioned $16.2 \mathrm{~mm}$ beneath the bottom of the CL mirror assembly. The excitation for CL measurements was provided at $25 \mathrm{kV}$ electron beam.

\section{RESULTS AND DISCUSSION}

\section{ESEM-EDS analyses}

Sediments CCCuS collected from the wet solid deposit of the mine drainage stream (Fig. 1b) were placed in an ESEM chamber. A first view showed mainly a particle size average of circa 50 microns and botryoidal textures, typical of colloidal masses in solutions, deposited layer by layer (Fig. 2a,b). This ESEM image taken by the backscattering (BS) probe displays onion-like textures of micro-spheres with strips of different grey-tones interpreted as chemical differences among layers (Fig. 2c). The EDS elemental chemical probe focused on more clear and darker similar BS areas offers spot analyses labeled 1 and 2 (Fig. 2a) exhibiting different ratios copper/carbon, much oxygen and accessorial zinc and sulfur. Aluminum and silicon can be attributed to impurities, e.g., feldspar, quartz, phyllosilicates from the sediments. These elementalchemical analyses could be associated with different proportions of carotenoid, copper and zinc hydroxides and accessorial sulfate minerals phases. Figures 2,a,b,c,d represent different enlargement views of the CCCuS at 40x, 20x, 10x and 1x performed in BS mode in environmental conditions of low pressure and high humidity to preserve the original hydration status of the sample and associated morphologies. These ESEM images mainly represent botryoidal hydrous copper globules growing in carotenoid matrix; in addition, carotenoid masses surrounded by hydrous copper complexes were also photographed. Biological structures were only observed in the carotenoid areas richer in carbon under the EDS chemical probe (Fig 2d).

\section{X-Ray Diffraction}


The initial selection of potential chemical elements helps to the Boolean searchmatching on the ICDD-PDF2 and RRUFF databases suggesting some PDF2 card files, as follows: quartz 83-0539 (peak $3.347 \AA$ ), hematite 83.0664 (peak $3.705 \AA$ ), euchlorine 83-1332 (peak $8.394 \AA$ ). These minerals are compatible with the Rio Tinto area paragenesis in which iron oxides and quartz are common phases [28]. The XPOWDER software analysis of the experimental XRD profile (Fig. 3a) shows the following semiquantitative mineralogical analysis for La Poderosa blue-green sediments collected from the acid mine drainage surface deposit: 36\% quartz (card 83-0539), 17\% hematite (830664), 47\% euchlorine (83-1332) or low-crystalline equivalent material. Density = $3.384 \mathrm{~g} / \mathrm{cm}^{3}$ and $\mu / \mathrm{Dx}$ of the mixture $=72.8 \mathrm{~cm}^{2} / \mathrm{g}^{-1}$. Other XRD patterns performed on additional aliquots contain variable amounts of feldspar, gypsum, chalcanthite, woodwardite and euchlorine phases. These last phases could be mixtures of nanocrystalline $\mathrm{Cu}$-Al-sulphate hydrotalcite-like compounds close to hydrowoodwardite $\left(\mathrm{Cu}_{1-\mathrm{x}} \mathrm{Al}_{\mathrm{x}} \quad\left[\mathrm{SO}_{4}\right]_{\mathrm{x} / 2}[\mathrm{OH}]_{2} \cdot \mathrm{mH}_{2} \mathrm{O}\right)$, i.e., similar the colloidal blue-green precipitate of Servetter-Chuc (Saint-Marcel, Aosta Valley, Italy) [29]. Our TG analysis data shows $27 \%$ of water in the mixture associated to both mineral and/or organic matter; the EDS data a $20 \%$ of carbon and the Raman spectra exhibits a main carotenoid spectrum plus additional amorphous materials. Accordingly, we also check our XRD spectrum with a theoretical pattern of carotenoid (Fig. 3a) which roughly fits in the experimental XRD pattern.

\section{X-Ray Fluorescence Spectroscopy}

The XRF spectrometric chemical analysis was performed on pressed pills (8 g) of powdered total sample of CCCuS including accessorial amounts of regional rocks of the sediments such as metapelites or rhyolites (Fig. 1b). It displays the following chemical analysis average: $\mathrm{SiO}_{2} 23.12 \% ; \mathrm{Al}_{2} \mathrm{O}_{3}$ 12.94\%; $\mathrm{Na}_{2} \mathrm{O}$ 1.16\%; $\mathrm{K}_{2} \mathrm{O}$ 0.94\%; $\mathrm{TiO}_{2}$ 0.35\%; $\mathrm{P}_{2} \mathrm{O}_{5} \quad 0.42 \%$ in agreement with the regional materials studied by the mining company [28]. Concerning, the $\mathrm{CaO} 1.16 \%$ and $\mathrm{MgO} 0.72 \%$ could be explained since the regional geology also includes beds of limestones, e.g., San Antonio body. The important amount of $\mathrm{SO}_{3} 10.91 \%, \mathrm{Fe}_{2} \mathrm{O}_{3} 17.03 \%$ and $\mathrm{MnO} 0.98 \%$ could be associated to the huge volcanic mineralization of pyrite and polymetallic phases and the subsequent gossans' covering formed by weathering. Concerning the metal amounts of $\mathrm{Cu} 5659$ ppm, Zn 655 ppm and Pb 51 ppm, they agree with average metallic contains of 
the San Antonio and San Dionisio metallic masses exhaustively analyzed by the mining Rio Tinto company [28]. Iron and copper sulphate-rich evaporative mineral precipitates are frequently observed in the Rio Tinto and La Poderosa areas [30]. In addition, the resultant pressed pills of $\mathrm{CCCuS}$ samples after the XRF analyses were X-irradiated samples with enhanced sensitization good enough to produce more intense luminescence emission [31].

\section{Raman-PL spectra}

La Poderosa CCCuS sample was identified as a carotenoid compound directly by Raman spectroscopy on the natural collected solid phase without extractions and/or concentrations. The experimental spectrum (Fig. 4) shows wave-number shifts in the main Raman bands of carotenoid compounds: $v_{1}(C=C$ stretching $)$ at $1520 \mathrm{~cm}^{-1}, v_{2}(C-$ $\mathrm{C}$ stretching $)$ at $1154 \mathrm{~cm}^{-1}$ and $\mathrm{v}_{3}\left(\mathrm{C}-\mathrm{CH}_{3}\right.$ deformation $)$ at $1006 \mathrm{~cm}^{-1}$ [32]. However, the overtones as well as the combination bands of the beta carotene are not present pointing roughly to a carotenoid compound such as xanthophylls or carotene. For instance, beta-carotene use to emit polarized bands of the all-trans isomer at 1586 and $1513 \mathrm{~cm}^{-1}$ being both resonant with the $1 \mathrm{Bu} \leftarrow 1 \mathrm{Ag}$ absorption around $440 \mathrm{~nm}$. In addition, the $1586 \mathrm{~cm}^{-1}$ band of beta-carotene could be resonant with the $21 \mathrm{Bu} \leftarrow 1 \mathrm{Ag}$ absorption around $275 \mathrm{~nm}$ which is not appreciated in out experimental Raman spectra [33]. The experimental Raman spectra show also an appreciable background noise, low intensity of the Raman emissions and a rising slope starting from $3000 \mathrm{~cm}^{-1}$ attributable to the other component of the mixture which are the copper hydrous complexes. The Raman identification of specific carotenoids must be made with caution using the progressive shift in wave-number of the $\mathrm{C}=\mathrm{C}$ stretching band in the conjugated polyene chain of carotenoids together with the number of $\mathrm{C}=\mathrm{C}$ groups [32]. From our experimental Raman spectra we infer the following assumptions: (i) stress in the carotenoid lattice by the minor changes observed in the frequency of the Raman peaks or presence of another carotenoid, being also possible that more than one carotenoid are present, (ii) good quality of carotenoid lattice on basis of the full width half maximum (FWHM) of the main Raman bands comparable to those of beta-carotene standard, (iii) low amount of carotene in sample in accordance with the low intensities of the Raman peaks. Beyond the Raman line-shape of the phonon spectra, at longer wavelengths of the spectrum, we observe photoluminescence peaks useful to estimate energies band- 
gap. The incident laser beam penetrates inside into the hydrous complexes producing both a probable dehydration together with the luminescence emission. Figure 4 shows some low PL emission at longer wavelengths, probably associated with hydrous copper compounds operating during the analysis such a complex physical model of thermal spike [34].

\section{Thermal Analyses by DTA, TG and TL}

The DTA-TG curves (Fig. 5a) obtained in $\mathrm{N}_{2}$ atmosphere shows an initial drop up to circa $325^{\circ} \mathrm{C}$ involving approximately a $18 \%$ of weight loss with difficult differentiation among molecular water, hydroxyl groups and volatile organic compounds. No clear steps were observed below this temperature. Beyond the $400^{\circ} \mathrm{C}$ almost certainly do not exists hydroxyl groups and curves show a plain behavior up to the interval $600-650^{\circ} \mathrm{C}$ in which the leaks out gases produces weight loss. Finally at $900^{\circ} \mathrm{C}$, the $\mathrm{CCCuS}$ complexes exhibit a total weight loss of circa $27 \%$. Figures 5 b,c display TL emissions of a natural as received aliquot (Fig. 5b) and other identical aliquot but X-irradiated one hour into the X-ray fluorescence spectrometer tube involving the characteristic additional heating produced by X-irradiation (Fig. 5c). A comparative observation of Figures 5a, 5b and 5c suggests us the following comments: (i) it exist clear relationships between the main thermo-differential, thermo-gravimetric and thermo-luminescent curve features, (ii) the most important TL emission is observed in natural aliquots at $140^{\circ} \mathrm{C}$ and $\mathrm{X}$-irradiated aliquots at $168^{\circ} \mathrm{C}$, this temperature lift up is a common physical effect observed in near all materials, (iii) the DTA-TG gap curves from RT to circa $325^{\circ} \mathrm{C}$ suggest a probable dehydration involved in the main TL emission, (iv) the X-irradiated aliquot shows a 100 times more intense TL emission than the natural aliquot which is also a common physical feature, but (v) the single natural TL peak at $140^{\circ} \mathrm{C}$ changes in $\mathrm{X}$-irradiated aliquots to an improved profile peaked at $168^{\circ} \mathrm{C}$ with a shoulder at $200^{\circ} \mathrm{C}$ suggesting two different emission centers, (vi) the natural TL peak at $330^{\circ} \mathrm{C}$ raises from 15 to 450 arbitrary units of photonic intensity of TL emission and does not exhibit thermal displacement remaining at $330^{\circ} \mathrm{C}$ suggesting to be related more with carotenoid than with intrinsic hydroxyl features much more sensitive to this temperature.

Spatially and spectrally resolved Cathodoluminescence 
CCCuS blue micro-particles were placed in the ESEM microscope to be studied under the MONOCL3 cathodoluminescence probe in environmental mode avoiding the sample metallization allowing flow out the internal CL emission produced under the electron beam. Figure 6a depicts the study area under the BS probe including brighter zones richer in copper and darker zones richer in carotenoid compounds. Figure $6 \mathrm{~b}$ represents panchromatic CL emission of the same study area in which conversely carotenoid areas show more luminescence emission whilst copper-bearing zones does not emit light probably by two reasons: more water and more copper, since copper in minerals luminescence is usually considered only as an effective quencher. Nevertheless, it is also well known that a bright blue luminescence is emitted from $\mathrm{Cu}^{+}$ ions in inorganic solids by UV light irradiation [35, page 223]. Figure 6c displays an ESEM image with EDS spot analysis of a $\mathrm{CCCuS}$ particle previously X-irradiated strongly one hour under the XRF spectrometer with a resultant visible cracking. Figure 6d joint together CL spectra collected from the carotenoid-bearing zone, X-irradiated $\mathrm{CCCuS}$ to enhance the CL sensitivity and yellow-transparent amber from the Baltic Sea analyzed by $\mathrm{CL}$ in the same conditions. The amber pattern was selected from our internal spectra CL database of organic compounds exhibiting CL peaks at 325, 430 and $470 \mathrm{~nm}$. In addition, for comparison purposes we also included a published fluorescence spectrum of salicylic acid in bromoform [36]. La Poderosa CCCuS sample shows CL peaks at 430 and $470 \mathrm{~nm}$ probably associated to intra-molecular hydrogen bonds $(\mathrm{C}=\mathrm{O} \ldots \mathrm{OH})$, these luminescence spectra bands are commonly observed in many polynuclear aromatic hydrocarbons with carboxyl and hydroxyl groups; these groups make possible intra-molecular proton transfer in their lowest excited state producing these observed luminescence spectra (Fig. 6d) [36-38]. Carotenoid Raman bands at 1665 and $1652 \mathrm{~cm}^{-1}$ are generally interpreted as $\mathrm{C}=\mathrm{O}$ stretching modes. The accessorial little peak of CL at $325 \mathrm{~nm}$ observed in the sample is also frequent in coals being attributed to non-bridging oxygen hole centers ( $\equiv \mathrm{Si}-\mathrm{O} \bullet$ ) [39]. CCCuS complexes could be formed as amorphous globules of $\mathrm{Cu}(\mathrm{OH})_{2}$ (spertiniite) and/or $(\mathrm{Cu}, \mathrm{Zn})_{4}(\mathrm{OH})_{6}\left(\mathrm{SO}_{4}\right)$, (sulfo-atacamite) and hydrowoodwardite $\left(\mathrm{Cu}_{1-\mathrm{x}} \mathrm{Al}_{\mathrm{x}} \quad\left[\mathrm{SO}_{4}\right]_{\mathrm{x} / 2}[\mathrm{OH}]_{2} \cdot \mathrm{mH}_{2} \mathrm{O}\right)$ interbedded with carotenoid layers, including biofilm masses, and probably protein groups bonded with $\mathrm{Cu}^{+}$and $\mathrm{Cu}^{2+}$ cupro-proteins as we infer from the luminescence emissions. Both experimental luminescence spectra here provided, i.e., CL and PL performed on of $\mathrm{CCCuS}$ aliquots exhibit different spectral curve shapes. This dissimilarity could be 
explained since PL uses an energetic and penetrative laser source (532 nm) producing oxidation, heat, dehydration and atomic transport by self-diffusion. Conversely, CL is a different luminescence technique, low penetrative since the electron-beam concern only to surfaces. CL emission was recorded at low vacuum under water pressure and probably generating less analytical dehydration, oxidation and internal ionic selfdiffusion. The CL emission of carotenoid compounds is sensitized under X-irradiation exhibiting a more intense and identifiable CL spectrum. The study of biomarkers by luminescence of remote sensing has the inconvenience of the low luminescence emission operating directly on solid samples without dissolution-extraction procedures. Here we observe as the luminescence emission of carotenoid mixed together with lowluminescent metallic salts could be enhanced in-situ by irradiation under radiation sources of short wavelengths. Assuming that Mössbauer measurements onto the Mars surface are taken by placing the instrument's sensor head directly against a rock sample during about 12 hours for each sample, we reasonably calculate that samples could absorb an important gamma ray energy from the short irradiation source of the Mössbauer device enhancing the potential luminescence emission [40].

La Poderosa mine CCCuS complexes under ESEM-EDS are mainly composed by carbon, oxygen and copper elements distributed in areas enriched in carotenoid while other more mineralized areas are richer in hydrated copper oxides, accessorial sulfates and probably carbonates. Operating at one micron enlargement in the ESEM the carotenoid-bearing areas display clear structures of biological origin. The close association between both areas could facilitate potential bounds $\mathrm{Cu}$-protein to form enzymes involved in many biological processes including carotenoid synthesis. It is well know the capacity of copper initiating oxidative damage and interfering with important cellular events [40]. La Poderosa specimen shows a carotenoid Raman pattern together with a broad PL band excited under the laser beam at $532 \mathrm{~nm}$. Possible cuproenzymes associated to carotenoid could explain the broad band of the PL spectrum, e.g., ceruloplasmin which is a $\mathrm{Cu}$ binding protein containing six $\mathrm{Cu}$ atoms in both cupric $\mathrm{Cu}(\mathrm{II})$ and cuprous $\mathrm{Cu}(\mathrm{I})$ states, in addition, $\mathrm{Cu}$ could also bind to other proteins, e.g., albumin, transcuprein or histidine [41]. La Poderosa mine CCCuS complexes could be originated by algal growth and subsequent lysis due to environmental stresses and desiccation of the aquatic environment. The Rio Tinto Basin exhibits interesting 
environmental and cultural stimulants for biosynthesis of carotenoids from microalgae, fungi and bacteria as great sunlight, temperature fluctuation and important supplementation of metal ions such as $\mathrm{Cu}$ and accessorial $\mathrm{Zn}, \mathrm{Mn}$ and $\mathrm{Fe}$ [2]. Microorganisms could accumulate several types of different carotenoids as a part of their response to various environmental stresses [42]. A good genetic model for our case, for instance, could be the photoautotrophic microalgae Dunaliella sp., i.e., a major reported producer of carotenoids, requiring high light-intensity coupled with salt stress and nutrient limitation for both growth and carotenoid synthesis [43].

\section{CONCLUSIONS}

The studied solid sediments collected in mine drainages of La Poderosa mine (El Campillo, Huelva, Spain) are carotenoid complexes produced by algal growth and further lysis due to environmental stresses and desiccation of the original aquatic environment which force the microorganisms to accumulate carotenoids. The area exhibits interesting environmental and cultural stimulants for biosynthesis of carotenoids from microalgae, fungi and bacteria such as great sunlight, temperature fluctuation and important supplementation of metal ions such as $\mathrm{Cu}$ and accessorial $\mathrm{Zn}$, $\mathrm{Mn}$ and Fe. Here we find carotenoids in saline sediments analyzed directly in the solid state by molecular and luminescent spectroscopy techniques to identify solid carotenoids avoiding dissolution and pre-concentration treatments, since the hydrous copper-salted paragenesis do not mask the Raman emission of carotenoids. We also observed as X-irradiation pretreatments enhance the cathodoluminescence spectra emission of carotenoid enough to distinguish organic compounds including hydroxyl and carbonyl groups. In despite of the relative low geochemical abundance of the copper element, these $\mathrm{CCCuS}$ complexes could be a potential biomarker and useful proxy for understanding remote mineral formations as well as for terrestrial environmental investigations related to mine drainage contamination including biological activity and photo-oxidation processes. Intrinsic analytical difficulties in this study are the progressive re-crystallization of the copper salts along with desiccation and the high variety of carotenoids to be identified in the Raman spectrometer.

\section{ACKNOWLEDGMENTS}


This research was supported by the Spanish Ministry of Sciences and Innovation, project CGL2010-17108/BTE and CSIC project 201230E125. The authors acknowledge the help of Dr. M. Hernandez-Marine in the taxonomical description of the algae.

\section{REFERENCES}

[1] L. J. Preston, J. Shuster, D. Fernandez-Remolar, N.R. Banerjee, G.R. Osinski, G. Southam, Geobiology 9 (2011) 233-249.

[2] S. Sabater, T. Buchaca, J. Cambra, J. Catalan, H. Guasch, N. Ivorra, I. Muñoz, E. Navarro, M. Real, A. Romani, J. Phycol 39 (2003) 481-489.

[3] L.A. Amaral-Zettler, M. Messerli, A. Laatsch, P. Smith, M. L. Sogin. Biol. Bull 204 (2003) 205-209.

[4] H.N. Cannon, C.R. Stocker, S.E. Dunagan, K. Davis, J. Gómez-Elvira, B.J. Glass, L.G. Lemke, D. Miller, R. Bonaccorsi, M. Branson, S. Christa, J.A. RodríguezManfredi, E. Mumm, G. Paulsen, M. Roman, A. Winterholler, J.R. Zavaleta. J. Field Robot 24 (2007) 877-905.

[5] R. Navarro-González, K.F. Navarro, J. De La Rosa, E. Iñiguez, P. Molina, L.D. Miranda, P. Morales, E. Cienfuegos, P. Coll, F. Raulin, R. Amils, C.P. McKay, PNAS 103 (2006) 16089-16094.

[6] G. A. Armstrong, J. E. Hearst, FASEB J 10 (1996) 228-237.

[7] B. R. Green, D. G. Durnford, Annual Review of Plant Physiology and Plant Molecular Biology, 47 (1) (1996) 685-714.

[8] P. Jordan, P. Fromme, H. T. Witt, O. Klukas, W. Saenger, N.Krauß, Nature, 411 (6840) (2001) 909-917.

[9] K. K. Niyogi, O. Björkman, A .R. Grossman, PNAS 94 (25) (1997) 14162-14167.

[10] V. Irazusta, C. G. Nieto-Peñalver, M. E. Cabral, M. J. Amoroso, L.I.C. de Figueroa. Process Biochem 48 (2013) 803-809. 
[11] F. Khachik, G.R., Beecher, N.F. Whittaker, J. Agr Food Chem, 34 (4)(1986) 603616.

[12] A. Moraleda-Muñoz, J. Pérez, M. Fontes, F. J. Murillo, J. Muñoz-Dorado. Mol Microbiol 56 (2005) 1159-1168.

[13] A. J. Conner, K. C. Benison, Astrobiology, 13 (9) (2013) 850-860.

[14] S. Fendrihan, M. Musso, H. Stan-Lotter. J. Raman Spectr. 40 (12) (2009) 19962003.

[15] P. Vítek, J. Jehlička H.G.M. Edwards, K. Osterrothová, Anal. Bioanal. Chem. 393 (8) (2009) 1967-1975.

[16] M. Baranska, R. Baranski, E. Grzebelus, M. Roman, Vibr. Spectrosc. 56 (2011) 166-169

[17] P. Vítek, K. Osterrothová, J. Jehlička, Planet Space Sci, 57 (4) (2009) 454-459.

[18] J. De Gelder, K. De Gussem, P. Vandenabeele, L. Moens, J. Raman Spectr. 38 (9) (2007) 1133-1147.

[19] R. Withnall, B.Z. Chowdhry, J. Silver, H.G.M. Edwards, L.F.C. De Oliveira, Spectrochim Acta A 59 (10) (2003) 2207-2212.

[20] R. Nakamura, S. Yamamoto, J. Nakahara, J Chem Phys 117 (2002) 238-247.

[21] T. Bosak, B. Liang, T. D. Wu, S. P. Templer, A. Evans, H. Vali, J.L. GuerquinKern, V. Klepac-Ceraj, M.S. Sim, J. Mui, Geobiology 10 (2012) 384-401.

[22] J. Komárek, J. Perman J (1978) Review of the genus Dictyosphaerium (Chlorococcales). Algol. Stud. 20 (1978) 233-297

[23] C. Bock, T. Pröschold, L. J. Krienitz. Phycologia 47 (2011) 638-652.

[24] V. Jurado, A.Z. Miller, S. Cuezva, A. Fernandez-Cortes, D. Benavente, M.A. Rogerio-Candelera, J. Reyes, J.C. Cañaveras, S. Sanchez-Moral, C. Saiz-Jimenez, C. Constr. Build. Mater. 53 (2014) 348-359. 
[25] L. Forget, J. Ustinova, Z. Wang, V.A.R. Huss, B.F. Lang. Mol. Biol. Evol. 19 (2002) 310-319.

[26] M. Hujslová, A. Kubátová, M. Chudicková, M. Kolarik. Mycol. Progress 9 (2010) $1-15$.

[27] A.J. Flewelling, J.A. Johnson, C.A. Gray. Bot. Mar. 56 (2013) 287-297.

[28] F. Garcia Palomero, in: Recursos Minerales de España (eds Garcia-Guinea, J Martinez-Frías, J) 1992. pp. 1324-1351. Ed. CSIC Madrid.

[29] S. Tumiati, G. Godard, N. Masciocchi, S. Martin, D. Monticelli. Eur. J. Miner 20 (2008) 73-94.

[30] T. Buckby, S. M. L. Black, M. L. Coleman, M. E. Hodson, Mineral. Mag. 67 (2003) 263-278.

[31] M. J. Aitken Thermoluminescence dating. Ed. Academic Press, London, 1985. pp 359.

[32] V.E. Oliveira, H.V. Castro, H.G.M. Edwards, L.F.C. Oliveira. Carotenes and earotenoids in natural biological samples: a Raman spectroscopic analysis. J. Raman Spectrosc. 41 (2009) 642-650.

[33] S. Saito, M. Tasumi, C. H. Eugster, J. Raman Spectr. 14 (5) (1983) 299-309.

[34] A. Miotello, R. Kelly. Nucl Instrum Meth B 122 (1997) 458-469.

[35] Gaft, M, Reisfeld, R, Panczer, G Modern Luminescence Spectroscopy of Minerals and Materials. (2005) Ed. Springer-Verlag. Berlin, 2005.

[36] G.S. Denisov, N.S. Golubev, V.M. Schreiber, S. H. S. Shajakhmedov, A.V. Shurukhina. J. Molec. Str. 436-437 (1997) 153-160.

[37] L. Kubera-Nowakowska, K. I. Lichszteld. Rev. Adv. Mater. Sci. 14 (1) (2007) 9096.

[38] B. Pan, D. Cui, C. S. Ozkan, M. Ozkan, P. Xu, T. Huang, F. Liu, H. Chen, Q. Li, R. He, F. Gao, J. Phys. Chem. C, 112 (4) (2008) 939-944. 
[39] I. Kostova, L. Tormo, E. Crespo-Feo, J.Garcia-Guinea. Spectrochim. Acta A: 91 (2012) 67-74.

[40] L. M, Gaetke, C. K. Chow. Toxicology 189 (2003) 147-163.

[41] E. Harris, Essential and Toxic Trace Elements in Human Health and Disease: An Update (ed Prasad, AS), (1993) pp.163-179. Ed Wiley-Liss.

[42] V. López-Rodas, F. Marvá, M. Rouco, E. Costas, A. Flores-Moya. Chemosphere 72 (2008) 703-707.

[43] S. Boussiba, A. Vonshak. Plant Cell Physiol 32 (1991) 1077-1082.

\section{FIGURE CAPTIONS}

Figure 1. (a). Natural drainage stream from Poderosa mine, Campillo, Huelva, Spain. (b). An intimate mixture of lysed algae and sediments due to drying of the stream bed is observed. (c). Alga in the stream. (d). Growth of the alga in the laboratory on a BG11 culture medium.

Figure 2.- (a) Backscattering image of a representative sample of $\mathrm{CCCuS}$ and copper phases under the scanning electron microscope at 40 microns. Chemical EDS spot analyses displaying variable $\mathrm{C} / \mathrm{Cu}$ ratios (carotenoid/Cu-phases), (2) The same sample at 20 microns exhibiting copper mineral deposition around carotene-bearing organic matter (3) Conversely, at 10 microns it is possible to observe copper phases covered by carotenoid, (4) Biological algae structures observed at 1 microns.

Figure 3.- X-ray diffraction plots of powdered blue CCCuS masses (a) exhibiting lowcrystalline patterns with quartz impurities of the ground, hematite and euchlorine. (b) the same XRD pattern together with a carotenoid XRD pattern for comparison.

Figure 4.- Raman spectrum of a CCCuS complex displaying the main Raman bands of carotenoid compounds: $v_{1}(C=C$ stretching $)$ at $1520 \mathrm{~cm}^{-1}, v_{2}(C-C$ stretching $)$ at 1154 $\mathrm{cm}^{-1}$ and $v_{3}\left(\mathrm{C}-\mathrm{CH}_{3}\right.$ deformation $)$ at $1006 \mathrm{~cm}^{-1}$ together with a $\beta$-carotene standard. 
Figure 5.- (a) Simultaneous differential thermal and thermo-gravimetric analyses of as received samples showing a $27 \%$ of weight loss below $380^{\circ} \mathrm{C}$ mainly attributable to molecular water and hydroxyl groups. (b) Thermoluminescence glow curve of the natural blue $\mathrm{CCCuS}$ masses. (c) Thermoluminescence glow curve of other X-irradiated aliquot.

Figure 6.- Cathodoluminescence emission from a X-irradiated aliquot of blue CCCuS: (a) Backscattering plot showing carotenoid and copper bearing zones (b) Panchromatic CL plot of the same analytical area in which carotenoid areas are more luminescent that copper areas ( $\mathrm{Cu}$ luminescence killer), (c) Total chemical EDS analysis of the Xirradiated particle area, (d) Spectral CL curves of natural carotenoid (low CL emission), $\mathrm{X}$-irradiated carotenoid (more luminescent spectrum), amber from the Baltic sea and salicylic acid exhibiting the same spectral luminescent features. 


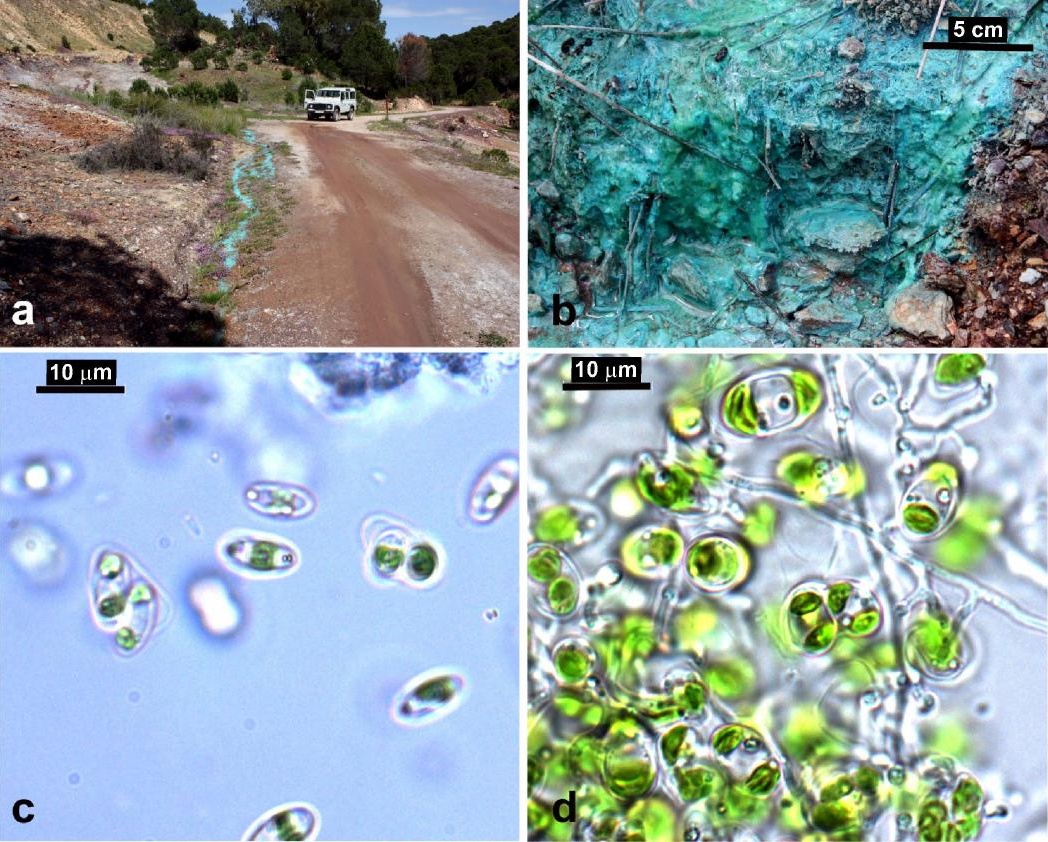




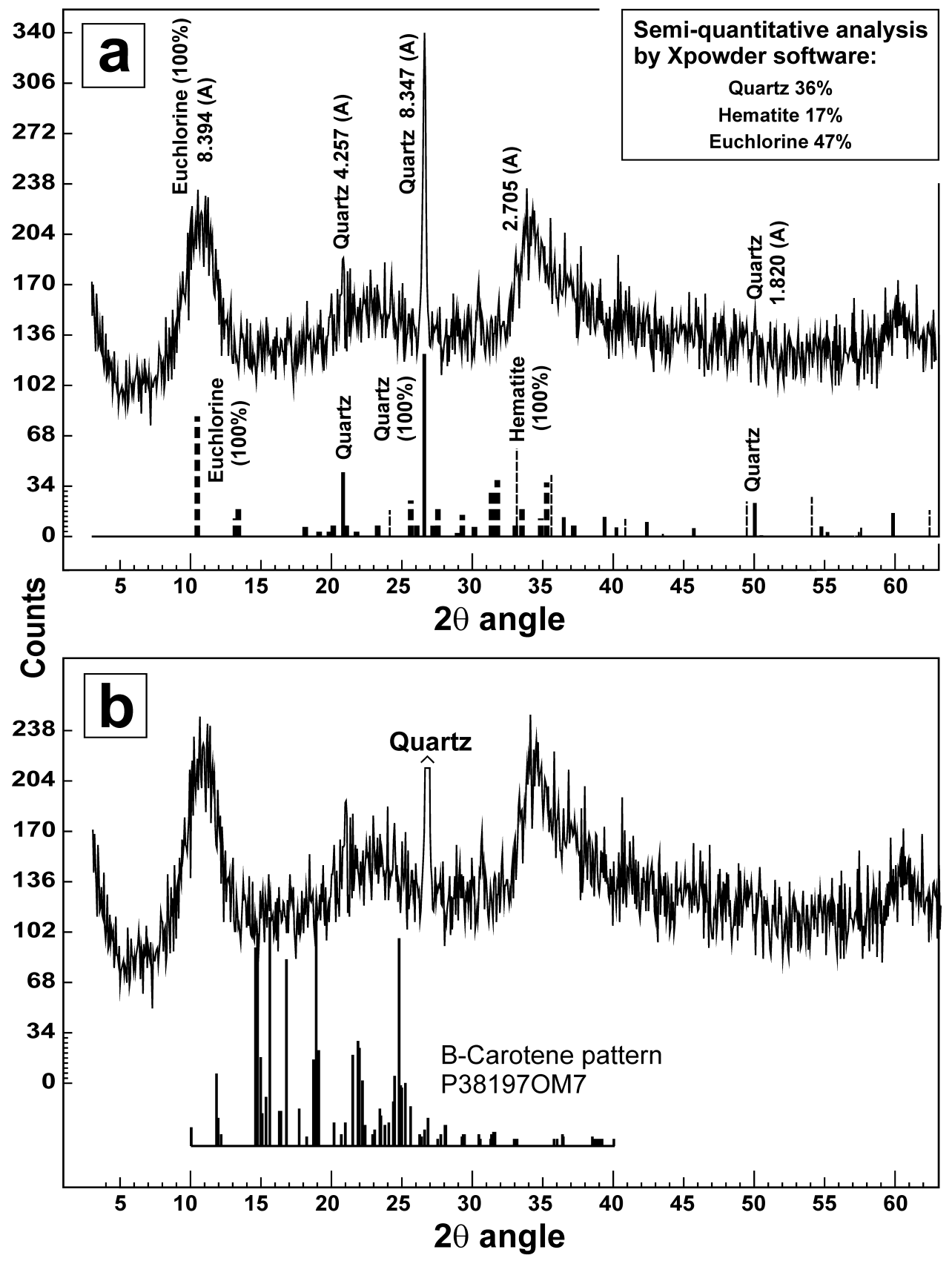




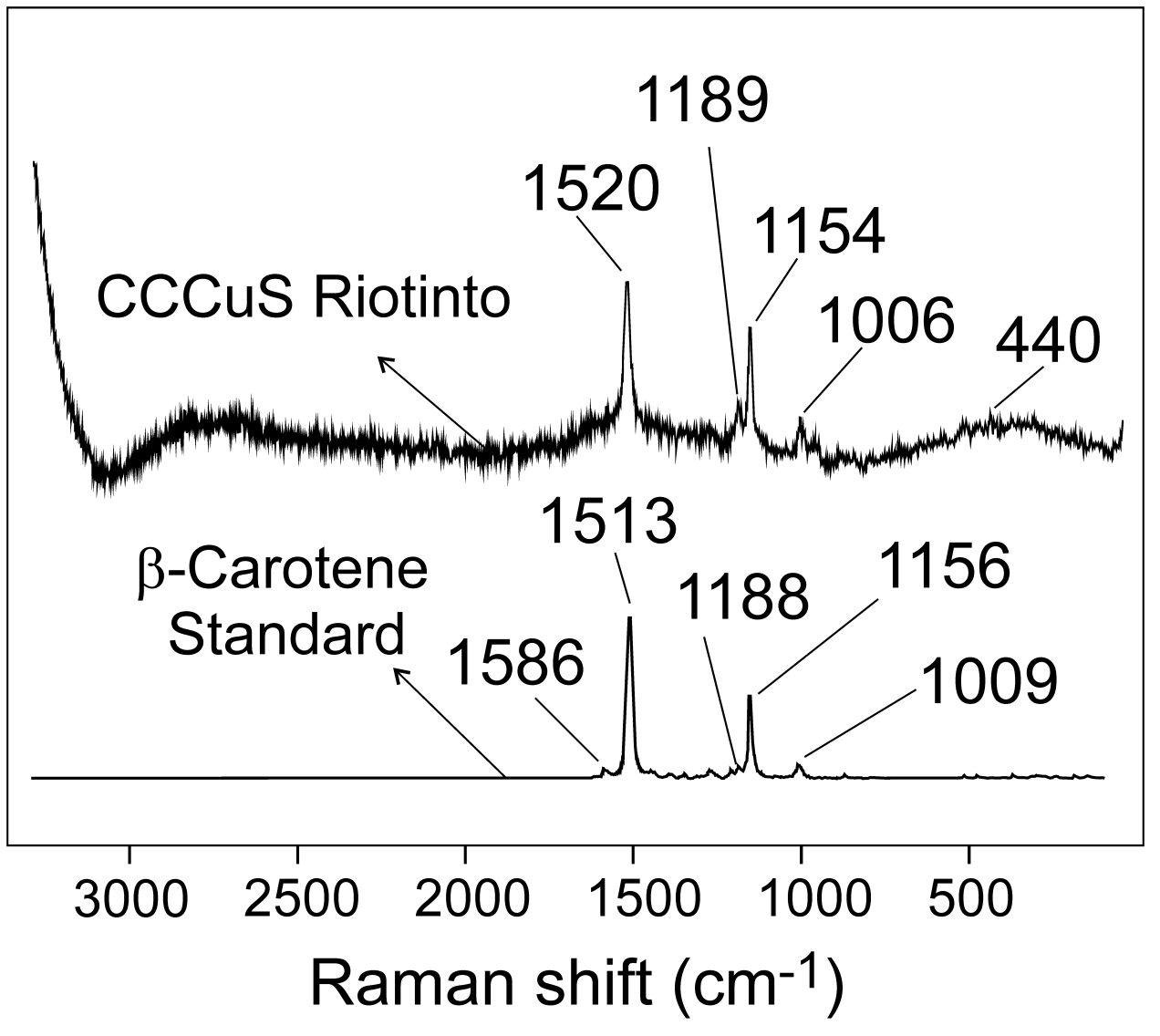



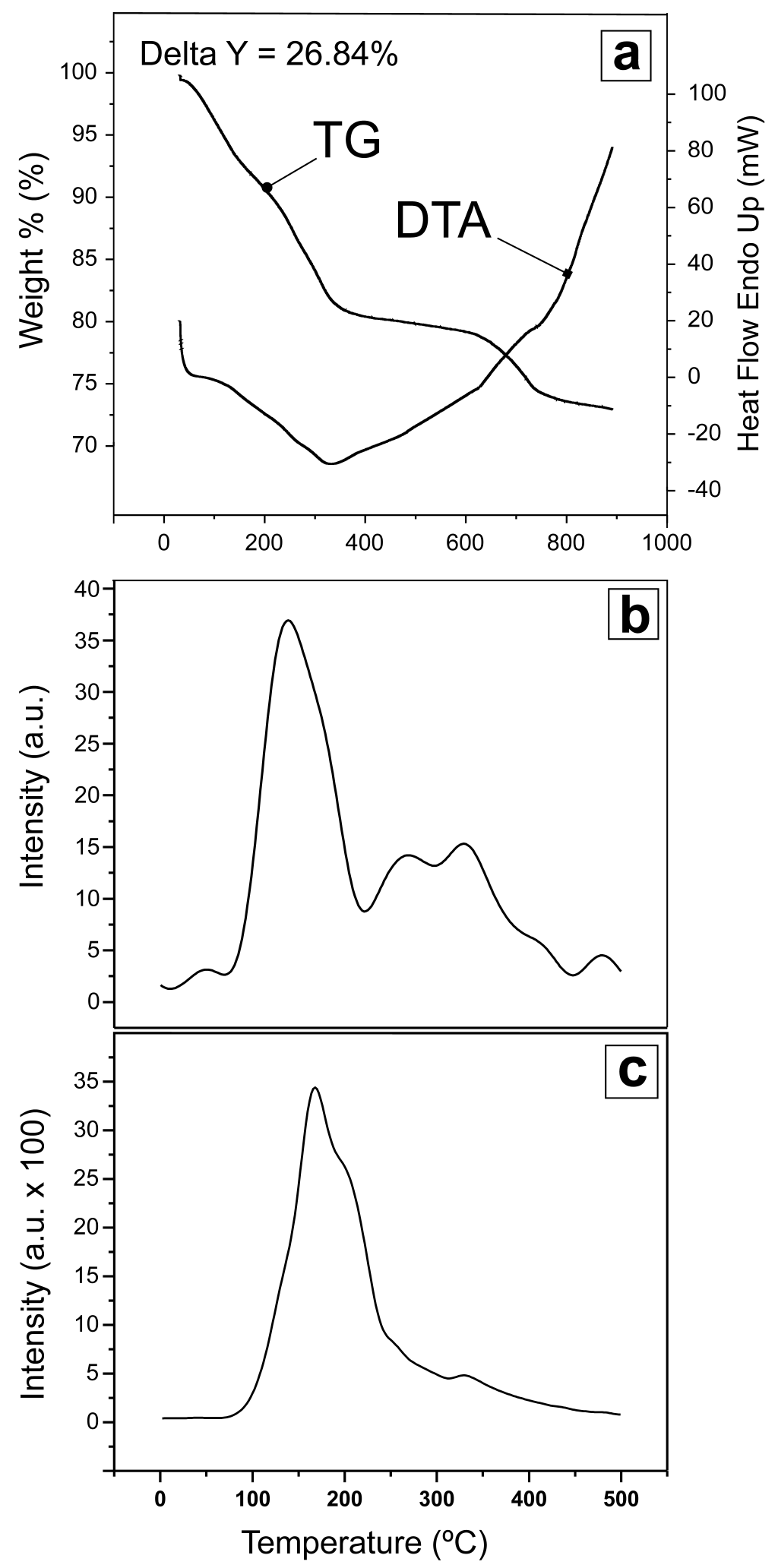

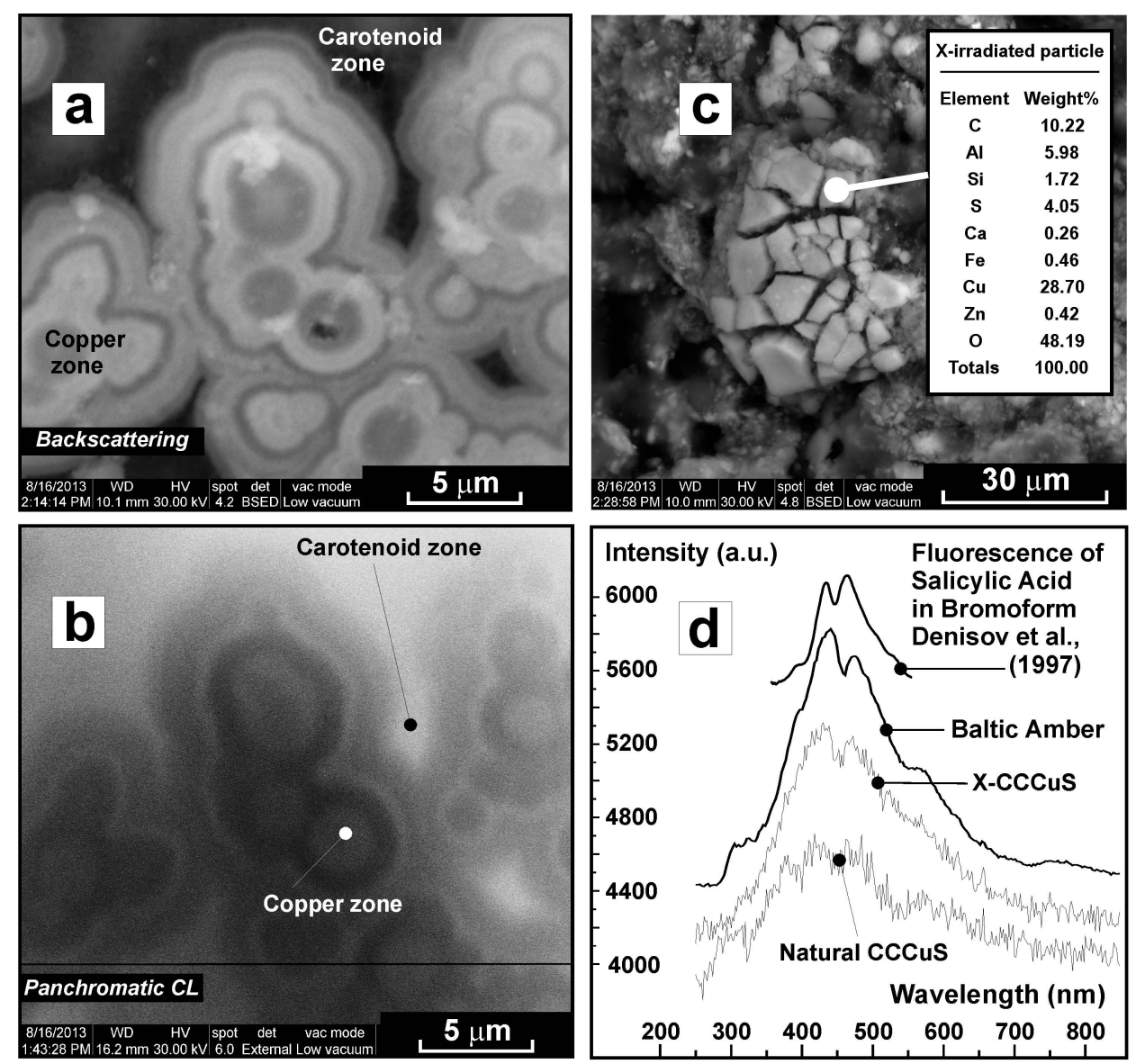